BULLETIN Bulletin hispanique

HISPANIQUE Université Michel de Montaigne Bordeaux

122-1 $\mid 2020$

Variations donjuanesques

\title{
Loreto Busquets, Ensayos de literatura comparada
}

UCOPress, Editorial Universidad de Córdoba, 2018

Córdoba,

Leonardo Martínez Carrizales

\section{OpenEdition}

12 Journals

Edición electrónica

URL: http://journals.openedition.org/bulletinhispanique/10977

DOI: 10.4000/bulletinhispanique. 10977

ISSN: 1775-3821

Editor

Presses universitaires de Bordeaux

Edición impresa

Fecha de publicación: 18 junio 2020

Paginación: 345-347

ISBN: 979-10-300-0592-9

ISSN: 0007-4640

Referencia electrónica

Leonardo Martínez Carrizales, «Loreto Busquets, Ensayos de literatura comparada», Bulletin hispanique [En línea], 122-1 | 2020, Publicado el 18 junio 2020, consultado el 19 enero 2021. URL: http://

journals.openedition.org/bulletinhispanique/10977 ; DOI: https://doi.org/10.4000/bulletinhispanique. 10977

Este documento fue generado automáticamente el 19 enero 2021.

Tous droits réservés 


\title{
Loreto Busquets, Ensayos de literatura comparada
}

UCOPress, Editorial Universidad de Córdoba, 2018

Córdoba,

\author{
Leonardo Martínez Carrizales
}

\section{REFERENCIA}

Loreto Busquets, Ensayos de literatura comparada. -Córdoba:UCOPress, Editorial Universidad de Córdoba, 2018, 425 p. Colección Excelencia, ISBN 10: 8499273602 - ISBN 13: 9788499273600

1 Loreto Busquets reunió en Ensayos de literatura comparada 11 artículos publicados entre 1988 y 2017 en revistas especializadas de España e Italia. El conjunto se completa con un trabajo inédito. El propósito de la profesora adscrita a la Universidad Católica del Sacro Cuore de Milán radicó en constituir mediante estos escritos un «panorama crítico orgánico y coherente» alrededor de una noción renovada del método comparatista en los estudios literarios. La reformulación de esta herramienta crítica supera por completo la práctica habitual del comparatismo consistente en documentar los vínculos intertextuales que enlazan artefactos literarios inscritos en diversos ámbitos lingüísticos, corroborando con ello que el espacio de la producción simbólica es trasnacional y transhistórico. Además de hacer suyo este supuesto teórico, eje del comparatismo tradicional, Loreto Busquets prueba en sus artículos que las relaciones interdisciplinarias, interdiscursivas e interartísticas verificadas entre diferentes obras constituyen los veneros más profundos de la comunidad simbólica de la creación humana.

2 En consecuencia, la lectura de Ensayos de literatura comparada depara a quien la lleve a cabo el conocimiento plausible y metodológicamente competente de vínculos estructurales entre, por ejemplo, la narrativa y la cinematografía, la poesía y la música, las ciencias sociales y la novela, la historia y los sistemas conceptuales que legislan el 
gusto histórico. Este interés dominante en el procedimiento crítico de Loreto Busquets se alimenta en un núcleo profundo: la consideración mimética de toda obra artística: «[...] es hoy opinión compartida que la interconexión de las artes es inherente a su condición misma por ser todas ellas imitativas y tener como objeto de imitación la realidad natural y humana, en razón del principio formulado por Locke, plenamente asumido por la estética de nuestros días, según el cual la Belleza no reside en el objeto (los cánones), sino en el sujeto que la percibe, en quien convergen las sensaciones y el juicio. Razón primera por la que el comparatismo [...] se [estima necesario] para una completa comprensión del impulso mimético que motiva las varias formas artísticas de expresión» (264-5265).

3 De este modo, la profesora Busquets reorganiza el campo de los estudios literarios de acuerdo con el apotegma mimético de matriz clásica, fundamento no sólo de las obras artísticas, sino también de toda facultad creativa desarrollada por los seres humanos, incluidos sistemas ideológicos de diversa índole. Esta perspectiva afirma que la facultad creativa de índole mimética afecta, además de las artes, el pensamiento social en sus diferentes organizaciones disciplinarias. Aquí radica el instrumento conceptual de mayor peso en el propósito de la autora por construir un espacio de estudio orgánico y coherente, alternativo a la distribución del campo de los estudios literarios llevada a cabo por el comparatismo tradicional, que reviste una consecuencia todavía más delicada en la estructura metodológica de los estudios literarios. Esta consecuencia estriba en la vinculación entre la obra artística y los sistemas conceptuales organizados de acuerdo con disciplinas del conocimiento político, histórico y social.

4 Según lo que advertimos en los artículos de la profesora Loreto Busquets, las formas simbólicas del arte sólo pueden ser plenamente comprensibles por medio de su inclusión en la trama conceptual de las poéticas que norman los criterios constructivos de los autores; tales tramas rebasan completamente el objetivo de actuar como oriente de la codificación formal de la obra de su valoración estética. En vez de ello, los universos conceptuales atinentes a la facultad mimética del ser humano anclan el arte en la estructura simbólica entera de la sociedad, donde historia, ideología, política, etcétera, no pueden ser excluidas, so pena de cancelar una vía de acceso a la comprensión cabal de los mecanismos que hacen verdaderamente inteligible y pertinente a la obra en una comunidad histórica de sentido.

5 La perspectiva desarrollada de este modo por la profesora Loreto Busquets en sus ensayos termina por plantear tácitamente que las obras artísticas del sistema comparado de la creación humana de base mimética son construcciones que funcionan social e históricamente como instrumentos de intervención de sus autores en sus respectivas comunidades y en las comunidades interpretativas diversas que se ocupan de tales obras. Este fenómeno es palmario cuando se examina, por ejemplo, la presencia de Mijail Bakunin en la narrativa de Vicente Blasco Ibáñez («El pensamiento de Bakunin en la tetralogía social de Blasco Ibáñez»). Sin embargo, el afán de intervención en la sociedad desplegado por los artistas que parece interesar más a Loreto Busquets, al grado de definir su propia personalidad intelectual y expresar plenamente las posibilidades heurísticas de su perspectiva, se caracteriza por una enérgica toma de posición a favor de la modernización de los lenguajes artísticos, la independencia crítica, autonomía del juicio, la liberalidad con respecto del orden establecido, el cosmopolitismo crítico y el eclecticismo enriquecedor de la visión del mundo. Por ejemplo, Loreto Busquets concluye la exposición sobre la historiografía literaria 
desarrollada por Alcalá Galiano afirmando que este hizo de la historia «un instrumento de lucha» y una contribución al progreso humano, por virtud «de haber adoptado una visión cosmopolita y una aproximación crítica y metodológica decididamente moderna» (87). No sólo a propósito de este personaje, sino también de Manuel de Falla («El mito de Atlántida: de Verdaguer a Falla y Halffter»), el Duque de Rivas («El romanticismo pictórico de los Romances históricos de Rivas») o Rafael Alberti («El renacimiento italiano en A la pintura de Alberti»), la autora expone con fortuna que la composición artística se lleva a cabo como consecuencia de la inmersión del autor en universos conceptuales de gran alcance, en modo alguno circunscritos al dominio de la estética, donde las opciones tomadas por el artista de acuerdo con su proyecto creativo lo convierten en un sujeto que interpreta el orden social y participa en éste mediante una actividad de compleja significación e influencia.

El comparatismo reformulado que da coherencia temática y metodológica a Ensayos de literatura comparada se asienta sobre la noción mimética de la obra artística. Aunque esta noción se alimentó de la matriz clásica de la cultura occidental que la profesora Loreto Busquets no sólo no desconoce sino que adopta en su análisis formal, la perspectiva crítica de ella insiste en que el procedimiento imitativo ocurre en el ámbito de sistemas conceptuales que atraviesan horizontalmente los discursos especializados de las artes y las disciplinas del conocimiento. En consecuencia, el comparatismo tiene como objeto final la investigación de los fundamentos constructivos de la inteligencia humana que otorgan sentido a la realidad, que la hacen inteligible y la vuelven pertinente con respecto de la acción social; fuera de esta capacidad constructiva, la realidad carece de sentido. «En una palabra: las cosas no gritan nada. Es el hombre quien las hace suyas incorporándolas en su mundo a través de su cuerpo, ojo y mente, y haciendo que se vuelvan carne en sus palabras. Con ello hace humano el mundo fenoménico absolutamente indiferente a las cosas humanas, poblándolas de objetos que de tal forma devienen a él afines y familiares» (111). Esta conversión al sentido humano, por así decirlo, se lleva a cabo gracias a procedimientos constructivos de índole mimética que no se circunscriben a los cánones de las disciplinas artísticas, sino que hacen suyo el dominio de los sistemas conceptuales propios de diversas formas del conocimiento. Tal es el verdadero alcance del comparatismo. La forma artística es la "plasmación o fijación de un sistema de creencias y de una visión de mundo que se enraízan en la situación histórico-ideológica en que aquellos se han producido (235)».

\section{AUTORES}

\section{LEONARDO MARTÍNEZ CARRIZALES}

Universidad Autónoma Metropolitana - Unidad Azcapotzalco 